\title{
An Assessment Model for Rating High-Threat Crop Pathogens
}

\author{
N. W. Schaad, J. Abrams, L. V. Madden, R. D. Frederick, D. G. Luster, V. D. Damsteegt, and A. K. Vidaver
}

First, fourth, fifth, and sixth authors: U.S. Department of Agriculture-Agricultural Research Service, Foreign Disease-Weed Science Research Unit, Ft. Detrick, MD; second author: Science Applications International Corporation, McLean, VA; third author: Ohio State University, Wooster; and seventh author: University of Nebraska, Lincoln. Accepted for publication 6 February 2006.

\begin{abstract}
Schaad, N. W., Abrams, J., Madden, L. V., Frederick, R. D., Luster, D. G., Damsteegt, V. D., and Vidaver, A. K. 2006. An assessment model for rating high-threat crop pathogens. Phytopathology 96:616-621.

Natural, accidental, and deliberate introductions of nonindigenous crop pathogens have become increasingly recognized as threats to the U.S. economy. Given the large number of pathogens that could be introduced, development of rapid detection methods and control strategies for every potential agent would be extremely difficult and costly. Thus, to ensure

wide, using the United States as an illustrative example. Previously, the AHP has been shown to work well for strategic planning and risk assessment. Using the collective knowledge of subject matter expert panels incorporated into commercial decision-making software, 17 biological and economic criteria were determined and given weights for assessing the threat of accidental or deliberately introduced pathogens. The rating model can be applied by experts on particular crops to develop threat lists, especially those of high priority, based on the current knowledge of individual diseases.
\end{abstract} the most effective direction of resources a list of high-threat pathogens is needed. We address development of a pathogen threat assessment model based on the analytic hierarchy process (AHP) that can be applied world-
Additional keywords: emerging pathogens, quarantine.
Reports of new and emerging crop pests and pathogens appear annually (2). Due to a geographic isolation from much of the world, many serious pathogens have been excluded from the United States. However, nonindigenous (exotic) species are an increasing threat to United States and North American agriculture due to a number of factors, especially increased world travel and free-trade agreements. In addition, a growing concern has emerged regarding the threat of deliberate introductions of plant pathogens $(23,27)$. The vulnerability of U.S. agriculture (including crops and forests) has been recognized by individuals and organizations (15), in particular, the National Research Council of the National Academy of Sciences. They concluded that deliberate introductions of crop pathogens pose a substantial threat to agriculture, and that the United States is not prepared to deal with such a threat (1).

There are numerous examples of recent introductions of nonindigenous plant pathogens and the subsequent economic losses that have resulted. Bacterial citrus canker has been a recurring problem in Florida since the early 1900s, and the pathogen has been eradicated several times at a cost of over $\$ 300$ million (25). After many legal challenges, another attempt to eliminate citrus canker has been ongoing for the past several years (8). The discovery of Karnal bunt of wheat in Arizona and California in 1996 (5,28), Plum pox virus in Pennsylvania in 1999 (12), and soybean rust in the southern United States in 2004 (24) are other recent examples of introduced pathogens. Ralstonia solanacearum race 3 biovar 2, which causes brown rot of potato and can result in severe losses to potatoes in temperate climates (16), is highly regulated by the European Union (6). Although brown rot has not been found in potato in the United States, the pathogen was found

Corresponding author: N. W. Schaad; E-mail address: norman.schaad@ars.usda.gov

DOI: 10.1094 /PHYTO-96-0616

This article is in the public domain and not copyrightable. It may be freely reprinted with customary crediting of the source. The American Phytopathological Society, 2006. in geranium in 1999 and 2001 (11). The \$100-million U.S. geranium industry has incurred large economic losses over the past 5 years due to quarantine regulations imposed upon the geranium flower industry $(7,9)$ in order to protect the billion-dollar potato industry. In these cases, eradication, containment, and quarantine issues are responsible for most of the immediate costs of the disease.

Nonindigenous plant pathogens are of great concern in all countries partly because domestic scientists often have insufficient knowledge about them, little or no experience working with them, and appropriate controls have not been tested under local production conditions (2). In addition, resistant cultivars normally are not available in a country's elite germplasm for nonindigenous pathogens, even if genes for resistance are available elsewhere. In order to control or eradicate a plant disease, one must first correctly identify the causal agent. Thus, the first line of defense against any plant pathogen, domestic or exotic, is its rapid detection and identification (22). With several thousand named diseases of major crops (15), and several new hosts and/or diseases being discovered every year, the development of reliable, accurate, and cost-effective detection protocols for every pathogen currently is not plausible. Developing techniques for detection, identification, and control of threatening foreign diseases is a major concern in plant pathology. An important step in this process is to determine which pathogens are of the greatest threat, so that crop security and disease management programs can be organized to deal effectively with accidental, natural, or deliberate introductions of pathogens. General and specific criteria are needed for each type of introduction.

There are several existing lists of high-threat plant pathogens, including one prepared by Weller et al. (26), the Australian Group (4), the preliminary American Phytopathological Society list of threatening pathogens (13), and the occasionally updated list from the ad hoc group of the Biological Weapons Convention (15). More recently, as a result of the Agricultural Bioterrorism Protection Act of 2002, the U.S. Department of Agriculture (USDA)Animal Plant Health Inspection Service (APHIS) has prepared an 
agent list of threatening plant pathogens (3). In most cases, it is not clear how these lists were prepared, what information was considered, who worked on list preparation, and what criteria (or weighting of criteria) were used (15).

Developing a list of threatening plant pathogens is a challenging task. General risk assessment models can be followed to determine the probabilities of disease introduction, disease establishment and spread, survival, economic impact, and ease of control or containment (15). However, some of these components require detailed epidemiological information and models (14). In the short or intermediate term, it is very unlikely that the detailed information or data needed to perform precise risk or epidemiological modeling will be available for the full range of possible threat agents. A potentially useful alternative is to employ subject matter experts (SMEs) to rate pathogens based on previously established and validated criteria. Some variation of this was used for the currently available lists, although there is much uncertainty in how the rating criteria were established and then put into practice. In some cases, the final decision may well have been made by one or two individuals.

There is a tendency, when faced with a complex problemsuch as determining where defensive efforts should be focused with respect to plant pathogens - to want to simplify the solution $(18,19)$. However, as with all complex problems, there are tradeoffs between accuracy and complexity in the representations. For instance, a reasonable criterion for a high-risk pathogen is that it has high infectivity. However, until a more thorough assessment is done, it is not clear how much weight should be given to such a criterion relative to other criteria, or even how to specify what is meant (quantitatively) by high virulence. Thus, a criterion of infectiousness (virulence) can be used in various, and possibly subjective and biased, ways.

\section{MATERIALS AND METHODS}

General methodology and expert panels. To assist in the development of objective threat lists of crop pathogens, we have developed a rating or scoring system based on the analysis of choices individuals made in an expert panel, regarding criteria (e.g., pathogen or disease traits) of value in characterizing plant pathogens. A panel of 16 SMEs was selected to represent mycology, virology, bacteriology, epidemiology, extension, molecular biology, strategic studies, academia, federal agencies, and interested clients. Two 2-day workshops sponsored by the USDA-Agricultural Research Service (ARS) were conducted during which key criteria that could be used in prioritizing pathogens were elicited and defined. Membership in the first and second panels was the same, except one government agency representative was replaced by one from academia. A previously reported preliminary numerical rating index based on 11 criteria was presented as a starting point $(15,21)$. To approach a reasonable level of objectivity, while capturing the complexity of the system and maintaining rating accuracy, the criteria were selected and organized into a logical hierarchy and their relative importance was determined using the analytic hierarchy process (AHP) developed by Saaty (17). This approach has been of value for strategic planning, technology trade-off studies, vendor selections, personnel evaluations, economic forecasts, and risk assessments (20). The overall goal of the workshops was to provide a structured process by which the disparate discipline and individual opinion of each participant could be incorporated into a single evaluation process using the implicit assumptions and knowledge that they each brought to the dialogue. Once the evaluation was developed, the panel determined the evaluation scale and the evaluation model was tested for validity against a small number of crop pathogens. The overall process is summarized in Figure 1.

Efforts to include a moderate number of experts strike a meaningful balance between accuracy and simplicity. The key criteria used in determining the importance of a threat pathogen are presented, while being flexible in assessing their relative value in a way that allows different assumptions to reflect different operating scenarios, leading to a dynamically adaptive threat list. The rating system can be used by such diverse groups as research scientists, government agencies, commodity groups, and large growers, because it is easily modified to fit the objectives of the user. Modifying the weights used for each criterion is easily done using commercially available software.

Analytical hierarchical process. Decisions that involve either choosing the best option from among a number of complex alternatives or ranking and prioritizing a list of complex alternatives that possess large numbers of characteristics can tax human judgment (17-19). This is particularly true when the candidate alternatives (or choices) are considered in their entirety and when they are presented simultaneously for consideration. This problem, for example, is faced whenever an individual or group attempts to decide which pathogen traits (criteria) are significant in determining a threat to a country, or how to rank the criteria. This decision-making situation is exacerbated by the fact that, usually, the alternatives possess attributes to two very different types of criteria: those that are easily and objectively measured versus those requiring the expression of some subjective preference for an attribute. An example of an objectively measured criterion would be the "production of a compound toxic to animals or humans" or "no chemical control available." In contrast, criteria such as "easily fermented or grown" or "virulence is high" are very subjective and dependent upon conditions and experience of the rater. The general steps involved in employing the AHP are presented below. A list of AHP definitions is presented in the Appendix.

Determine objective and preliminary list of criteria. The first step in developing a general framework for prioritization is choosing the criteria. The framework greatly affects the development of groups of criteria to consider for inclusion in the evaluation model. This involves brainstorming a preliminary list of criteria to consider for inclusion in the final evaluation model while always bearing in mind the specific details of the goal or objective of the prioritization. For each criterion, a description and consistent definition must be provided to ensure all participants understand its meaning and relevance to the evaluation. During this step, there is considerable dialogue between participants seeking clarification of terms. In our case, we developed a set of criteria for the natural, accidental, and/or deliberate release of plant pathogens. The development of the preliminary groups of criteria was accomplished using group decision support software (described below) designed to allow all participants to build the list simultaneously. This software also enhanced the process for conducting a preliminary assessment of the criteria developed.

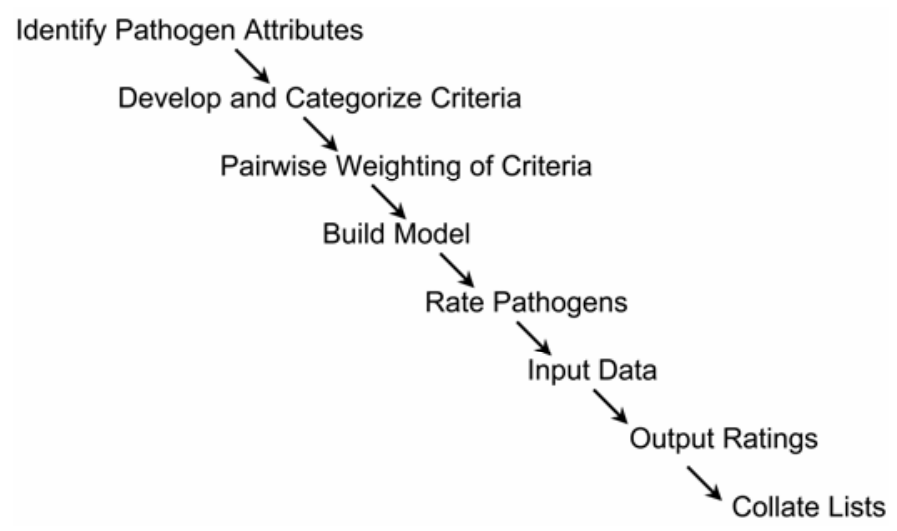

Fig. 1. Application of the analytical hierarchy process to develop and weight criteria, and rate high consequence pathogens. 
The second step is to conduct an assessment of the preliminary list of criteria with the objective of reducing their number, keeping only those that the participants believe provide some minimal amount of usefulness in the evaluation of alternatives. As mentioned above, we used group decision support software to assist in this prioritizing. Each participant placed the preliminary list of criteria in rank order in terms of importance to evaluating pathogens where the first item on their list was most important and the last item was least important. Each item on an individual's list was given numeric points based upon its rank position, with the most points assigned to the first item in the list and the least points assigned to the last item in that list. A rank sum of all the points assigned in each individual list for a specific criterion was then calculated and the list was presented in the rank order that reflects the priority of all participants. A discussion was held to determine whether or not all of the criteria were useful, given their rank order, for the evaluation of chosen pathogens.

Often, the criteria used to evaluate alternatives are not equally important or useful in that evaluation. This is demonstrated by the rank ordering of the preliminary list of criteria as described above. A more thorough process for determining the relative importance of the final structured list of criteria is used in the AHP. A process is used in which criteria are presented to the participants one pair at a time for consideration of whether the two are equally important or useful and, if not equal, which of the two is more important or useful. This is known as a pair-wise comparison. Such comparisons are performed across all possible pairs of criteria subordinate to each group, beginning with the goal. Furthermore, if the participants determine that they are not equally important, then they are asked to express the degree to which certain criteria differ on a numeric scale that ranges from 1 to 9 , where the value 1 would mean they are equal and 9 means there is an extreme degree of difference.

Since the scale is applied to a pair of criteria, the scoring represents a relative degree of importance in favor of the criterion receiving a number $>1$ and the resulting score is expressed as a ratio. The structure of the hierarchy determines which pairs of criteria are directly compared in this manner. Only related criteria clustered under the same group (which is also called a node in the evaluation model) are compared. It should be noted that in the hierarchal structure of the criteria there is a single node at the top

TABLE 1. Master list of groups of criteria developed for rating threats from deliberate plant pathogen introductions

\section{Criteria}

\section{Pathogen properties}

1. Pathogen survives easily for long periods under field conditions

2. Organism produces toxin or other compound in planta toxic to animals/humans

3. Organism is easily manipulated genetically

4. Organism targets multiple hosts

5. Organism is easily disseminated or transmitted in nature

6. Affects yield

7. Virulence of pathogen is high

\section{Production and dissemination}

8. Pathogen is easily fermented or grown

9. Organism is easily introduced and not dependent upon weather conditions

10. Organism is seed-transmitted and breeder seed is often produced abroad

\section{Detection}

11. Organism is difficult to detect, often latent, escaping detection

12. Attributes of organism make it difficult to trace

\section{Controls}

13. No chemical controls available

14. No resistance available

\section{Impact}

15. Presence of organism would result in a negative psychological impact

16. Pathogen is of quarantine significance and affects trade

17. Presence of organism or product could greatly affect economics which is simply called goal and all criteria that are grouped under this single node at the top are compared pair-wise as described above. Once all of the pair-wise comparisons throughout the structure of the hierarchy are completed, these relative measures of importance or usefulness within groups are converted to absolute measures of importance or usefulness relative to the goal. Furthermore, through the use of matrix algebra and the calculation of eigenvalues for sets of simultaneous equations, the simple ratios expressed in the pair-wise comparisons throughout the hierarchy are converted to percentages (17). The final values derived for criteria at the lowest level or the bottom of the hierarchy represents the importance or usefulness of those criteria relative to the goal as a percentage of that goal. Where there are multiple criteria organized into a hierarchy, the AHP spreads the $100 \%$ assigned to the goal across all of the criteria of the hierarchy in proportion to the ratios expressed in the pair-wise comparisons. This process of spreading the percentage is called weighting the criteria.

Development of criteria and use of the AHP software. To support and enhance our selection of criteria and the evaluation of pathogens, we used Expert Choice software (version 9.5, Expert Choice, Arlington, VA), which is based on the AHP. During the first workshop (described above), we developed the criteria, conducted the preliminary assessment of the groups of criteria, and refined their definitions. To develop and select criteria, each participant had a keyboard and independently (without outside influence) entered as many criteria as they could think of utilizing an electronic meeting support system. The panel members brainstormed all the candidate criteria and, collectively, clustered similar and related groups of criteria to generate the final set of candidate criteria. The criteria were, in turn, given a preliminary ranking through a group voting process to cull down from a very large list of candidate criteria, some of which were similar, to the best criteria for inclusion in the evaluation model. The final voting process allowed each member of the panel to place all the criteria in rank order from 1 to $n$, without being influenced by others. These individual rankings were converted by the groupware into numeric values for each criterion. The sum and mean of each member's numeric value for every criterion was taken, and this led to a prioritized list of criteria that represented the preferences of the entire panel. Some of the lowest-ranking criteria were removed from consideration in the assessment model, resulting in a final list of 17 criteria.

Organizing criteria. During the second workshop, we organized the criteria into the hierarchy. The 17 criteria were organized under five groups: pathogen properties, production and dissemination, detection, controls, and impact (Table 1). For example, in our assessment model, impact was organized into three criteria: negative psychological impact, quarantine significance, and effect on economy. Detection was subdivided into two criteria: difficulties in detection and traceability (i.e., to a person, group, or to a geographic location). These criteria (two from detection and three from impact) are examples of the attributes of a pathogen for which evaluations are made and ratings are given.

Weighting of criteria. Also during the second workshop, all of the criteria were given specific weighting values (data not shown). Like the simpler culling process used in earlier parts of the workshop, the weighting process was used for determining which criteria were most important in determining the score of a given pathogen as a threat; however, it was a more thorough, rigorous, and precise method for determining how much more or less important one criterion was relative to others in the assessment.

The weights were determined independently by each panel member by assigning a lower or higher numerical value to each pair of criteria and hierarchical category, and the results were synthesized by the Expert Choice software. In the AHP approach, weights derived and the scores assigned are all expressed and maintained as ratios. Since objective measurements can be easily 
converted to ratio values, it is possible to mix qualitative and quantitative judgments within the AHP. This allowed us to overcome a deficit in a naive hierarchic decision tree methodology: the inability to mix types of criteria under one tree (19).

Pathogen rating scales. The panel felt that a three-point scale having the verbal labels of high, medium, and low was sufficient for use in the pathogen prioritization model. Furthermore, the panel agreed that one scale was applicable to all the criteria. Using the pair-wise comparison approach, the panel developed the values associated with the evaluation scale's verbal labels.

The AHP's employment of pair-wise comparisons of the relative importance of the decision criteria (weighting the decision tree) and in making judgments concerning the relative value of steps on the evaluation scale reduces the arbitrary characteristic of weighting decision criteria and evaluation scales that would dilute the effectiveness of a decision tree methodology.

Assignment of final scores. Using the criteria, each pathogen is given a low, medium, or high rating. A score for an individual pathogen is the sum of the products of a pathogen's score for each criterion multiplied with the criterion's weight, and it will vary on a scale that ranges from 0 to $100 \%$. For example, if one criterion in the exemplar model has a weight of $10 \%$, a high score is worth $10 \%$ added to the final score; a medium score is worth $5.6 \%$ added to the final score; and a low score is worth $1.1 \%$ added to the final score. A pathogen scoring a high on every criterion would be rated $100 \%$. When several individuals do the ratings, the total scores can be averaged.

All the candidates are then evaluated and scores assigned to each in terms of the criteria at the lowest level of the decision tree. The scores are then aggregated across all criteria for each candidate and a summary score is determined. The summary scores allow a comparison of candidates with respect to the goal of the decision.

\section{RESULTS}

Results of rating exercises for a small subset of threatening and emerging pathogens are presented in Table 2. The 17 criteria listed in Table 1 were applied to selected potato pathogens, under a deliberate introduction scenario. The subset of potato pathogens was selected arbitrarily by the SMEs to represent a taxonomic cross-section of emerging pathogens for this commodity. For the purposes of this manuscript, we felt that it was not prudent to identify relative weights of the criteria for individual scenarios.

After scoring by a smaller subgroup of SMEs in a session at the second workshop, potato pathogens appeared to cluster in groups according to final scores. Ralstonia solanacearum race 3 biovar 2 , Clavibacter michiganensis subsp. sepedonicus, and Heterodera rostochiensis were the highest rated pathogens, with scores of
$84.4,74.6$, and $71.7 \%$, respectively. Phytophthora infestans and Erwinia chrysanthemi had intermediate scores of 45.1 and $48.2 \%$, while Rhizoctonia solani, Potato leafroll virus, and Potato spindle tuber viroid scored the lowest at 29.0, 38.1, and 29.2\%, respectively.

\section{DISCUSSION}

The Expert Choice software performed well in conjunction with the panel of experts for choosing the criteria and assigning weights under the AHP methodology. The software enabled a complex problem to be broken down into more manageable elements: a framework that allowed judgments of all 16 participants to be based upon a methodical and equal consideration of each of the decision criteria. The important characteristics were identified and the choice of weights was transparent-the computer program made the choices based upon our pair-wise forced-choice of what was more important. The methodology, including the software program, is meant for multiple users with different goals. The software allows the user to easily adjust the weightings for each criterion. For example, if an evaluation of the risk for the natural introduction of endemic pathogens (perhaps for choosing state research priorities) into a new region is desired, adjustments could be made to assign a different percentage to all or some criteria. These adjustments are not simply arbitrary changes in the percentages, but are based upon expert evaluations with forced choices, allowing a transparent weight selection based upon collective expertise and knowledge. The described rating system is easily adapted for addressing deliberate, accidental, and natural disease outbreaks by assigning different weights to the criteria.

Potato pathogens scored under our AHP model could be grouped into high, intermediate, and low threat, based upon arbitrary break points of 40 and $70 \%$ in their final scores, with only Potato leafroll virus scoring near a break point (Table 2). Using the rating model does require adequate expertise. It is generally acknowledged that experts with knowledge of pathogens of multiple crops are becoming scarce, and that many individuals are reluctant to assign a score to a given pathogen under a specific criterion if they do not feel they are sufficiently qualified to do so. Attempts to utilize remote data collection using electronic or paper rating forms distributed to SMEs were largely unsuccessful due to low response rates (data not shown). Most SMEs felt that group exercises would be most useful to more effectively exploit the knowledge base within and among disciplines. Our results suggest that a pool of expert field pathologists with considerable knowledge is required. This problem has been discussed by Madden and Wheelis (15). To effectively rate groups of pathogens, we therefore recommend that a team of at least 10 to 12 plant disease experts be convened for each crop, to include one or more SMEs with field experience for each pathogen being

TABLE 2. Results of potato pathogens scored under a deliberate introduction scenario with the assessment model for high-threat crop pathogens

\begin{tabular}{|c|c|c|c|c|c|c|c|c|c|c|c|c|c|c|c|c|c|c|}
\hline \multirow[b]{3}{*}{ Pathogen } & \multicolumn{17}{|c|}{ Criteria $^{a}$} & \multirow[b]{3}{*}{ Total } \\
\hline & 1 & 2 & 3 & 4 & 5 & 6 & 7 & 8 & 9 & 10 & 11 & 12 & 13 & 14 & 15 & 16 & 17 & \\
\hline & \multicolumn{17}{|c|}{ Score $^{b}$} & \\
\hline Phytophthora infestans & M & $\mathrm{L}$ & M & $\mathrm{L}$ & $\mathrm{H}$ & $\mathrm{H}$ & M & M & $\mathrm{L}$ & $\mathrm{L}$ & $\mathrm{L}$ & $\mathrm{H}$ & $\mathrm{L}$ & $\mathrm{L}$ & M & $\mathrm{L}$ & $\mathrm{M}$ & 45.1 \\
\hline Rhizoctonia solani & $\mathrm{H}$ & $\mathrm{L}$ & M & $\mathrm{L}$ & M & $\mathrm{L}$ & $\mathrm{H}$ & M & $\mathrm{H}$ & $\mathrm{L}$ & $\mathrm{L}$ & $\mathrm{L}$ & $\mathrm{L}$ & $\mathrm{L}$ & $\mathrm{L}$ & $\mathrm{L}$ & $\mathrm{L}$ & 29.0 \\
\hline Heterodera rostochiensis & $\mathrm{H}$ & $\mathrm{L}$ & $\mathrm{L}$ & M & $\mathrm{H}$ & $\mathrm{L}$ & M & M & $\mathrm{H}$ & $\mathrm{L}$ & M & M & M & M & $\mathrm{H}$ & $\mathrm{H}$ & $\mathrm{H}$ & 71.7 \\
\hline Ralstonia solanacearum race 3 biovar 2 & $\mathrm{H}$ & $\mathrm{L}$ & $\mathrm{H}$ & $\mathrm{L}$ & M & $\mathrm{H}$ & $\mathrm{M}$ & $\mathrm{H}$ & $\mathrm{H}$ & $\mathrm{L}$ & $\mathrm{H}$ & M & $\mathrm{H}$ & M & $\mathrm{H}$ & $\mathrm{H}$ & $\mathrm{H}$ & 84.4 \\
\hline Clavibacter michiganensis subsp. sepedonicus & M & $\mathrm{L}$ & M & M & M & M & M & $\mathrm{H}$ & M & $\mathrm{L}$ & M & M & $\mathrm{H}$ & M & $\mathrm{H}$ & $\mathrm{H}$ & $\mathrm{H}$ & 74.6 \\
\hline Erwinia chrysanthemi & M & $\mathrm{L}$ & $\mathrm{H}$ & M & $\mathrm{H}$ & M & $\mathrm{L}$ & $\mathrm{H}$ & M & $\mathrm{L}$ & M & M & $\mathrm{H}$ & M & $\mathrm{L}$ & $\mathrm{L}$ & $\mathrm{L}$ & 48.2 \\
\hline Potato leafroll virus & $\mathrm{L}$ & $\mathrm{L}$ & $\mathrm{H}$ & M & $\mathrm{H}$ & M & $\mathrm{L}$ & $\mathrm{L}$ & $\mathrm{L}$ & $\mathrm{L}$ & $\mathrm{H}$ & $\mathrm{H}$ & $\mathrm{H}$ & $\mathrm{L}$ & $\mathrm{L}$ & $\mathrm{L}$ & M & 38.1 \\
\hline Potato spindle tuber viroid & $\mathrm{L}$ & $\mathrm{L}$ & $\mathrm{H}$ & M & M & M & $\mathrm{L}$ & $\mathrm{L}$ & $\mathrm{L}$ & $\mathrm{L}$ & M & M & $\mathrm{H}$ & $\mathrm{L}$ & $\mathrm{L}$ & $\mathrm{L}$ & $\mathrm{L}$ & 29.2 \\
\hline
\end{tabular}

a Table 1 provides a list of groups of criteria by number.

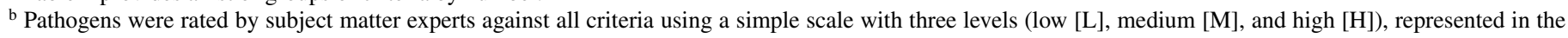
model by numerical values. 
rated. In this way, information can be exchanged between SMEs for making final judgments. Our experience underscores the lack of availability of highly trained field pathologists with knowledge of the epidemiology of foreign plant diseases. One positive result of exercises such as the workshops we convened is to highlight the critical data gaps for which information is needed to assess the relative threats posed. Such information is useful to stakeholders, funding agencies, and plant pathologists with interest in assessing the relative threats posed by plant pathogens foreign to their country.

Users should develop lists using the proposed criteria. The approach proposed here is certainly simpler than the complex risk-assessment or epidemiological approaches that others have proposed $(14,15)$, and it has the advantage of being useable immediately by using the collective knowledge of experts of diseases of particular crops. The model framework is consistent with the proposal for establishing a pathogen database (10), which, in principle, would be somewhat dependent upon the availability of our rating scheme. The ultimate utility of the proposed method for developing threat lists will be decided by individual research scientists and organizations studying exotic diseases and naturally introduced disease-causing agents.

This assessment model provides potential users such as ARS, APHIS, other federal and state agencies, and other users with a flexible tool to develop lists of emerging high-risk nonindigenous plant pathogens. The model allows considerable flexibility in that users can modify criteria and/or the weights assigned to the criteria to suit many specific introduction scenarios. The model can be applied to establish a list of low, moderate, and high-risk pathogens that might be introduced accidentally or deliberately so that resources can be made available for developing countermeasures. The availability of this rating model will further allow for the development of rapid detection assays and controls for those highly rated pathogens of the most important crops and plants.

We intend to make this model available in the future (Expert Choice software is required for model application).

\section{APPENDIX}

\section{Definitions related to the analytical hierarchy process.}

Alternative(s). A general term referring to one or more of the items which are under evaluation with respect to the criteria. For example, an alternative could be a pathogen such as wheat rust.

Candidate(s). A term used interchangeably with alternative(s).

Criterion, criteria. An attribute or characteristic of the candidates or alternatives about which some judgment or measurement can be made relative to the degree to which a specific candidate possesses the characteristic or meets the criterion. For example, one criterion might be: "organism is easily disseminated or transmitted in nature."

Evaluation. The process of assessing the alternatives with respect to the criteria regarding the degree to which a specific candidate possesses the characteristic or meets the criterion. For example, with regards to detection, one pathogen may be assessed as being very difficult to detect and given a rating of high while another would receive a rating of low.

Goal. The purpose or objective for which the evaluation is undertaken. The goal of this project was to prioritize pathogens in terms of their overall threat to crops.

Group. A major subdivision of the goal containing similar criteria.

Pair-wise. The process of presenting for assessment or evaluation at one time only a pair of items such as criteria or alternatives.

Rating label(s). The text or verbal descriptions associated with the degree to which a specific candidate possesses the characteristic or meets the criterion. For example, a set of rating labels might be high, medium, and low.
Ratings scale. The set of numeric values, expressed as percentages, associated with a set of rating labels that represent the degree to which a specific candidate possesses the characteristic or meets the criterion. For example, a set of rating labels like high, medium, and low could have the percentage values of 100 , 67 , and $33 \%$, respectively, associated with them.

\section{ACKNOWLEDGMENTS}

We acknowledge the active participation of R. Hickson, K. J. Leonard, S. A. Lommel, R. Murch, G. A. Payne, D. C. Sands, and M. Urlaub in our workshops. Mention of a trademark or proprietary product does not constitute a guarantee or warranty of the product by the U.S. Department of Agriculture and does not imply its approval to the exclusion of other products that may also be suitable.

\section{LITERATURE CITED}

1. Anonymous. 2002. Countering Agricultural Bioterrorism. National Research Council, National Academy Press, Washington, DC.

2. Anonymous. 2002. Predicting Invasions of Nonindigenous Plants and Plant Pests. National Research Council, National Academy Press, Washington, DC.

3. APHIS. 2004. Agriculture Select Agent Program. Published online by APHIS Select Agent Program. http://www.aphis.usda.gov/programs/ ag_selectagent/index.html.

4. Australia Group. 2005. List of plant pathogens for export control. Published online by The Australia Group. http://www.australiagroup.net/ en/control_list/plants.htm.

5. Bonde, M. R., Peterson, G. L., Schaad, N. W., and Smilanick, J. L. 1997. Karnal bunt of wheat. Plant Dis. 81:1370-1377.

6. Council of the European Union. 1998. Council directive 98/57/EC of 20 July 1998 on the control of Ralstonia solanacearum (Smith) Yabuuchi et al. Off. J. Eur. Communities, L-235:1-39.

7. Goldsmith, R. 2003. New rule, new disease. Grower Talks 60:24/67.

8. Gottwald, T. R., Hughes, G., Graham, J. H., Sun, X., and Riley, T. 2001. The citrus canker epidemic in Florida: The scientific basis of regulatory eradication policy for an invasive species. Phytopathology 91:30-34.

9. Hammer, P. A. 2003. Ralstonia lessons. Grower Talks 66:66.

10. Kang, S., Ayers, J. E., De Wolf, E. D., Geiser, D. M., Kuldau, G., Mooman, G. W., Mullins, E., Uddia, W., Correll, J. C., Deckart, G., Lee, Y.-H., Martins, F. N., and Subbarao, K. 2002. The internet-based fungal pathogen database: A proposed model. Phytopathology 92:232-236.

11. Kim, S. H., Olson, T. N., and Schaad, N. W. 2002. Ralstonia solanacearum biovar 2 race 3 in geraniums imported from Guatemala to Pennsylvania in 1999. (Abstr.) Phytopathology 92(suppl.):S42.

12. Levy, L., Damsteegt, V., and Welliver, R. 2000. First report of Plum pox virus (sharka disease) in Prunus persica in the United States. Plant Dis. 84:202.

13. Madden, L. V. 2001. What are the nonindigenous plant pathogens that threaten U.S. crops and forests? APSnet Feature. Published online by The American Phytopathological Society, St. Paul, MN. http://www.apsnet.org/ online/feature/exotic/.

14. Madden, L. V., and van den Bosch, F. 2002. A population-dynamics approach to assess the threat of plant pathogens as biological weapons against annual crops. BioScience 52:65-74.

15. Madden, L. V., and Wheelis, M. 2003. The threat of plant pathogens as weapons against U.S. Crops. Annu. Rev. Phytopathol. 41:155-176.

16. Meshechkina, Z. F., and Bermicheva, N. C. 1984. Brown rot of potato in the Ural. (In Russian) Trudi Ural Agric. Inst. 40:43-46.

17. Saaty, T. L. 1982. Decision Making for Leaders: The Analytical Hierarchy Process for Decisions in a Complex World. Lifetime Learning Publications, Belmont, CA.

18. Saaty, T. L. 1990. Decision Making for Leaders. RWS Publications, Pittsburgh, PA.

19. Saaty, T. L. 1990. The Analytic Hierarchy Process. RWS Publications, Pittsburgh, PA.

20. Saaty, T. L., and Vargas, L. G. 2000. Models, Methods, Concepts and Applications of the Analytic Hierarchy Process. Kluwer Academic Publishers, Boston, MA.

21. Schaad, N. W. 1999. What is an effective pathogen? (Abstr.) Phytopathology 89(suppl.):S145.

22. Schaad, N. W., Frederick, R. D., Shaw, J., Schneider, W. L., Hickson, R., Petrillo, M. D., and Luster, D. G. 2003. Advances in molecular-based diagnostics in meeting crop biosecurity and phytosanitary issues. Annu. Rev. Phytopathol. 41:305-324. 
23. Schaad, N. W., Shaw, J. J., Vidaver, A., Leach, J., and Erlick, B. J. 1999. Crop biosecurity. APSnet Feature. Published online by The American Phytopathological Society, St. Paul, MN. http://www.apsnet.org/online/ feature/biosecurity/.

24. Schneider, R. W., Hollier, C. A., Whitam, H. K., Palm, M. E., McKemy, J. M., Hernández, J. R., Levy, L., and DeVries-Paterson, R. 2005. First report of soybean rust caused by Phakopsora pachyrhizi in the continental United States. Plant Dis. 89:774.

25. Schubert, T. S., Rizvi, S. A., Sun, X., Gottwald, T. R., Graham, J. H., and
Dixon, W. N. 2001. Meeting the challenge of eradicating citrus canker in Florida-again. Plant Dis. 85:340-356.

26. Weller, R. E., Lyu, C. W., and Atlas, R. M. 1999. Universities and the biological and toxin weapons convention. ASM News 65:403-409.

27. Wheelis, M., Casagrande, R., and Madden, L. V. 2002. Biological attack on agriculture: Low-tech, high-impact bioterrorism. BioScience 52:569576.

28. Ykema, R. E., Floyd, J. P., Palm, M. E., and Peterson, G. R. 1996. First report of Karnal bunt of wheat in the United States. Plant Dis. 80:1207. 